\section{Deadlines Calendar}

Fellowships, grants, etc.

31 December 1984

16 January 1985

15 June 1985

15 June 1985

Call for papers

1 March 1985

Other

11 January 1985

15 January 1985

15 January 1985

31 January 1985

8 February 1985
Alan T. Waterman Award (this issue, p. 1229)

NRC Postdoctoral Fellowships for Minorities

(this issue, p. 1200)

Macelwane Annual Award (this issue, p. 1238)

Hanks and Orville Scholarships (this issue, p. 1238)

CIMMS International Symposium on Variational Methods in Geosciences (October 1984 Bulletin, p. 1082)

NSF College Science Instrumentation Program proposals (this issue, p. 1220)

National Research Council Senior and Postdoctoral Research Associateship applications (this issue, p. 1185)

Research Opportunities for Women proposals (this issue, p. 1208)

Workshop on the Correction of Precipitation Measurements (this issue, p. 1229)

NCAR/RAF flight requests (October 1984 Bulletin, p. 1082)

\section{For Members Only.... wear it with pride!

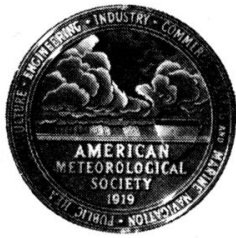

Due to the many requests over the years from members and AMS Chapters, the AMS is offering a very attractive lapel pin/tie tack combination to its members. The Seal of the American Meteorological Society is masterfully reproduced and die-struck on the finest jeweler's metal with a polished Hamilton Gold-clad finish. The size is $\frac{\mathbf{3}}{\mathbf{4}}$ " in diameter.

Because of the limited supply, we suggest that you order your AMS lapel pin/tie tack combination now.

\section{$\$ 8.00$}

\section{AMERICAN METEOROLOGICAL SOCIETY 45 Beacon St. Boston, MA 02108}

\title{
50 years ago $\ldots$
}

\section{NEW JOURNALS AND SOCIETIES*}

The Journal of the Aeronautical Sciences

Beginning with January, 1934, the Institute of Aeronautical Sciences, Inc., with the cooperation of the American Institute of Physics, Inc., is publishing a new quarterly, The Journal of the Aeronautical Sciences, which will be the official publication of the Institute and devoted to papers on theoretical, experimental and applied science as employed in aeronautics. Dr. J. C. Hunsasker, Mass. Inst. of Technology, is the editor. Articles of interest to meteorologists in the first three numbers include: Turbulence and skin friction by Th. von Kármán, Air force measurements on bodies moving through still air by R. H. Smith and J. Van H. Whipple, Comments on meteorrological research by C. G. Rossby, Fluid flow near a smooth surface by A. Fage, in the January number (v. 1, no. 1); Turbulence companion of Reynolds number by H. L. Dryden, North American air mass properties by H. C. Willett, in the April number (no. 2); Research on fog at the Round Hill Research Station of the Massachusetts Institute of Technology by H. G. Houghton, in the July number (no. 3).

Some quotations from Rossby's incisive "Comments on Meteorological Research":

"One of the greatest obstacles to progress in meteorology is undoubtedly to be found in the wide gulf between the mathematical theory on the one hand and the applied science on the other. In meteorological research, experimental verification is usually impossible ... the chief difficulty lies in the number of variables involved even in the simplest of phenomena. To eliminate all but one of these variables, two methods are possible. Utilizing a great number of obser- vations, one may group the observed effect with respect to one selected variable, assuming the random distribution of the other elements to be the same in each group. This might be true if assurance could be had that the variables really are mutually independent but this, unfortunately, is seldom the case. The other method consists in a study of individual cases, a procedure which has gained increased favor with the advent and ascendance of the Norwegian Meteorological School. The chief drawback to this method consists in the obvious opportunities it offers for a biased selection of evidence in favor of a preconceived theory. It is no wonder, then, that meteorological theory in many cases has degenerated into pretty pieces of mathematical exhibition, where the postulates lack all resemblance to the conditions actually found in the air and where the results can not be checked. . . . This . . has caused such a deep distrust, particularly in the United States, of theoretical investigations that synoptic meteorologists have restricted themselves to an accumulation of weather-map experience which is seldom or never interpreted except in the most superficial sense. Education in even elementary classical phsics is not considered necessary or even desirable ... the principal task of any meteorological institution of education and research must be to bridge the gap between the mathematician and practical man, that is to make the weather man realize the value of a modest theoretical education and to induce the theoretical man to take an occasional glance at the weather map. The polar front theory, beyond a doubt, represents the most successful effort as yet to bridge the gulf that separates the two meteorological camps.

*Bull. Amer. Meteor. Soc., 15, 265-266. 